\title{
HUBUNGAN PENGUASAAN KOSAKATA DENGAN KEMAMPUAN MEMBACA CEPAT SISWA KELAS X IPA 6 SMA NEGERI 1 CURUP TAHUN PELAJARAN 2016/2017
}

\author{
Gendis Siti Hatmanti ${ }^{1}$, Syukri Hamzah ${ }^{2}$, dan Agus Trianto ${ }^{3}$ \\ ${ }^{1,2,3}$ Program Studi Pendidikan Bahasa dan Sastra Indonesia \\ Jurusan Pendidikan Bahasa dan Seni \\ FKIP Universitas Bengkulu \\ Sgendis@yahoo.com
}

\begin{abstract}
Abstrak
Penelitian ini bertujuan untuk menguji hubungan penguasaan kosakata dengan kemampuan membaca cepat siswa kelas X IPA 6 SMA Negeri 1 Curup. Jenis Penelitian ini adalah korelasi. Populasi penelitian adalah siswa kelas X IPA 6 SMA Negeri 1 Curup. Sampel penelitian adalah siswa kelas X IPA 6 sejumlah 30 siswa, diambil dengan menggunakan teknik sampel jenuh. Pengumpulan data menggunakan tes. Uji instrumen dilakukan dengan uji keterbacaan, uji validitas, dan uji reliabilitas, uji daya beda dan uji tingkat kesukaran. Teknik analisis data yang digunakan adalah analisis korelasi product moment. Hasil penelitian menujukkan bahwa: (1) penguasaan kosakata siswa secara keseluruhan memperoleh skor rata-rata 69.11 yang termasuk dalam kategori tinggi; (2) kemampuan membaca cepat (KEM) siswa secara keseluruhan memperoleh skor rata-rata 224.87 yang termasuk dalam kategori tinggi; (3) terdapat hubungan yang signifikan antara penguasaan kosakata dengan kemampuan membaca cepat siswa kelas X IPA 6 SMA Negeri 1 Curup sebesar 0.53 ( $r_{\text {hitung }}=0.53$ pada taraf signifikansi $5 \%$ dengan $N=30, r_{\text {tabel }}=0,36$, dan $\left.r_{h}>r_{t}\right)$. Berdasarkan data hasil penelitian tersebut dapat disimpulkan bahwa terdapat hubungan yang signifikan antara penguasaan kosakata dengan kemampuan membaca cepat siswa kelas X IPA 6 SMA Negeri 1 Curup tahun pelajaran 2016/2017.
\end{abstract}

Kata kunci: kosakata, membaca cepat, korelasi

\begin{abstract}
This research aims to examine the relationship of mastery of vocabulary with the fast reading ability students class X IPA 6 senior high school number 1 Curup. This type of research is correlation. The population of the research is the students of class X IPA 6 senior high school number 1 Curup. The sample of the research is the students of class X IPA 6 senior high school number 1 Curup totaling 30 students, taken using saturated sample technique. Data collection using test. The instrument test is performed with legibility test, validity test, reliabity test, different power test and difficulty test. Data analysis technique used is product moment correlation analysis. The result showed that: (1) mastery of the vocabulary of students as a whole got an average score of 69.11 included in the high category; (2) students overall reading ability (KEM) scored an average score of 224.87 which was included in the high category; (3) there is a significant correlation between vocabulary mastery with fast reading ability of student class X IPA 6 senior high school number 1 Curup equal to 0.53 ( $\mathrm{rh}=$ 0.53 at significance level $5 \%$ with $\mathrm{N}=30, \mathrm{rt}=0.36$, and $\mathrm{rg}>\mathrm{rt}$ ). Based on the data of the research result can be concluded that there is a significant relationship between mastery of vocabulary with fast reading ability of student class X IPA 6 senior high school number 1 Curup in 2016/2017 academic year.
\end{abstract}

Keywords: Vocabulary, fast reading, correlation

Hubungan Penguasaan Kosakata dengan Kemampuan Membaca Cepat Siswa Kelas X IPA 6 SMA Negeri 1 Curup Tahun Pelajaran 2016/2017 


\section{PENDAHULUAN}

Membaca merupakan salah satu keterampilan dalam berbahasa yang perlu diperhatikan. Hal ini karena membaca memegang peranan penting sebagai dasar untuk dapat menggali banyak informasi, termasuk ilmu pengetahuan dan teknologi yang terus berkembang. Menurut Dalman (2013: 5) membaca merupakan suatu kegiatan atau proses kognitif yang berupaya untuk menemukan berbagai informasi yang terdapat dalam tulisan. Dari informasi-informasi tersebut tentunya akan menambah wawasan para pembaca tergantung dengan kebutuhan bacaannya.

Terampil dalam membaca dapat menjadikan siswa memahami dengan baik semua materi pelajaran yang disajikan saat proses pembelajaran. Menurut Dalman (2013:8), di sekolah, pembelajaran membaca perlu difokuskan pada aspek kemampuan memahami isi bacaan. Jadi dalam hal ini siswa benar-benar ditekankan untuk memahami isi dari bacaan yang mereka baca, karena dengan begitu, para siswa akan mengetahui informasi dengan rinci tanpa menghafal suatu bacaan itu melainkan memahaminya.Agar siswa mampu membaca dengan cepat dan dapat memperoleh informasi dengan baik, maka siswa perlu mengetahui teknik dalam membaca.

Salah satu teknik dalam membaca adalah membaca cepat, menurut Widiatmoko (2011:19) membaca cepat adalah perpaduan antara kecepatan membaca dengan pemahaman isi bacaan. Tujuannya adalah untuk mengidentifikasi dan memahami makna dari bacaan tersebut sefesien mungkin dan kemudian mentransfer informasi tersebut dalam memori jangka panjang dalam otak. Jadi, dalam hal ini siswa benar-benar dituntut untuk dapat membaca dengan kecepatan dan pemahaman yang tinggi, tidak hanya sekedar bisa membaca dengan cepat namun bisa memahami isi bacaan secara menyeluruh. Dengan kata lain kecepatan efektif membaca siswa haruslah memadai.

Berdasarkan hasil berbagai survei, minat baca orang Indonesia sangatlah rendah, hal ini sesuai dengan hasil survei UNESCO yang menyatakan bahwa minat baca masyarakat Indonesia baru 0,001 persen. Artinya, dalam seribu masyarakat hanya ada satu masyarakat yang memiliki minat baca (Gobekasi. "Survei UNESCO: Minat Baca Mayarakat Indonesia 0,001 Persen". 7 Januari 2017. Http://gobekasi.com). Selanjutnya, berdasarkan studi "Most Litterate Nation In the World" yang dilakukan oleh Central Connecticut State University pada Maret 2016 lalu, Indonesia dinyatakan menduduki peringkat ke-60 dari 61 negara soal minat membaca masyarakatnya (Kompas. "Minat Baca Indonesia Ada di Urutan Ke-60 Dunia". $7 \quad$ Januari 2017. http://edukasi.kompas.com). Selain hal tersebut hasil observasi awal di sekolah juga menyatakan bahwa minat baca siswa tergolong rendah hal ini dibuktikan dengan rendahnya persentase kunjungan pustaka para siswa. Para siswa hanya melakukan kunjungan pustaka jika mendapatkan tugas dari guru. Artinya kegiatan membaca hanya siswa lakukan pada saat-saat tertentu saja dan jarang dilatih. Jarang berlatih membuat siswa kurang terampil dalam kegitan membaca. Padahal, pembelajaran Bahasa Indonesia pada kurikulum 2013 ini berbasis teks. Siswa akan terus berinteraksi dengan berbagai jenis teks, tentu dalam hal ini kemampuan membaca para siswa harus lebih baik agar siswa mampu memahami isi teks dengan cepat dan tepat.

Oleh karena itu, kegiatan latihan merupakan faktor yang penting untuk meningkatkan kecepatan efektif membaca, begitu juga dengan penguasaan kosakata. yang akan membantu siswa untuk dapat memahami suatu bacaan dengan cepat dan tepat. Penguasaan kosakata dapat diartikan sebagai kemampuan untuk memahami 
kata-kata yang digunakan dalam suatu bahasa Menurut Tarigan (1985: 2) kualitas keterampilan berbahasa seseorang jelas bergantung kepada kuantitas dan kualitas kosakata yang dimilikinya. Artinya, dapat diasumsikan bahwa semakin baik penguasaan kosakata seseorang maka semakin besar pula sumbangannya terhadap kemampuan dalam memahami sebuah wacana dengan cepat dan tepat.

Berkaitan dengan hal-hal yang diketahui di atas, paparan ini akan mengungkapkan tentang penguasaan kosakata mempunyai hubungan yang signifikan terhadap kemampuan membaca cepat siswa. Dalam penelitian ini, penulis memilih SMA Negeri 1 Curup. Hasil observasi awal di SMA Negeri 1 Curup, diperoleh informasi bahwa sekolah ini telah menerapkan kurikulum 2013. Kegiatan membaca cepat juga merupakan bagian dari aspek pengajaran membaca yang diajarkan oleh guru di sekolah, selain itu untuk menambah perbendaharaan kosakata pada siswanya, guru juga menganjurkan siswa untuk membaca dari berbagai sumber. Penulis memilih kelas $X$ IPA 6 berdasarkan hasil belajar siswa dalam mata pelajaran Bahasa Indonesia. Kelas $X$ IPA 6 merupakan kelas yang memiliki nilai rata-rata Bahasa Indonesia tertinggi di antara kelas lainnya. Berdasarkan hal tersebut penulis mengharapkan hasil yang optimal dari penelitian ini sehingga dapat menjadi kelas percontohan bagi kelas lainnya untuk lebih meningkatkan prestasi belajarnya.

1. Kemampuan Membaca Cepat

a. Hakikat Membaca

Membaca adalah suatu kegiatan interaktif untuk memetik serta memahami arti atau makna yang terkandung di dalam bahan tulis. Di samping itu membaca juga merupakan suatu proses yang dilakukan serta dipergunakan oleh pembaca untuk memperoleh pesan yang hendak disampaikan penulis melalui media kata-kata atau bahan tulis. Menurut Harjasujana (1997:36, dalam Somadayo, 2011:5) membaca adalah suatu kegiatan komunikasi interaktif yang memberikan kesempatan kepada pembaca dan penulis untuk membawa latar belakang dan hasrat masing-masing.

Tujuan utama dalam membaca adalah untuk mencari serta memperoleh informasi, mencakup isi, memahami makna bacaan.

b. Membaca Cepat

Salah satu teknik dalam membaca adalah membaca cepat. Menurut Ahmad (2010:41) membaca cepat adalah membaca dengan kecepatan tinggi, hampir keseluruhan materi dibaca. Widiatmoko (2011:19) mengatakan bahwa membaca cepat adalah perpaduan antara kecepatan membaca dengan pemahaman isi bacaan.

c. Kecepatan Efektif Membaca (KEM) Kecepatan Efektif Membaca (KEM) merupakan perpaduan antara kecepatan membaca dengan kemampuan memahami isi bacaan, Harjasujana dan Mulyati (1996: 55). Jadi, dalam hal ini terdapat dua aspek yang dinilai dalam KEM ini, yaitu kecepatan dan pemahaman isi. Dengan demikian, KEM adalah kecepatan yang harus dimiliki pembaca tanpa mengabaikan pemahaman terhadap isi secara menyeluruh.

Berikut ini rumus yang dapat digunakan untuk mengukur kecepatan efektif membaca (Trianto, 2004: 9).

$\frac{\text { Jumlah kata dalam teks }}{\text { Waktu baca per menit }} X \ldots \%$ Pemahaman $=\cdots \mathrm{Kpm}$ 
Keterangan:

\% Pemahan: Skor yang didapat : skor maksimal x 100

Berdasarkan

hasil

pengkajian oleh para ahli membaca

di Amerika, kecepatan yang memadai untuk siswa lulusan SD \pm $200 \mathrm{kpm}$; tingkat SLTP antara 200$250 \mathrm{kpm}$; tingkat SLTA antara 250$325 \mathrm{kpm}$; dan tingkat mahasiswa antara 325-400 kpm dengan pemahaman minimal $70 \%$. (Trianto,2004: 9).

2. Penguasaan Kosakata

a. Kosakata

Menurut Djiwandono (1996:

42) sebagai bagian dari komponen bahasa, kosakata terdiri dari kata-kata yang digunakan dalam komunikasi melalui bahasa, baik penggunaan bahasa secara lisan maupun secara tertulis.

b. Penguasaan Kosakata

Menurut Tarigan (1985: 2) kualitas keterampilan berbahasa seseorang jelas bergantung kepada kuantitas dan kualitas kosakata yang dimilikinya. Berdasarkan pendapat tersebut jika dikaitkan dalam konteks membaca, selanjutnya dapat dikatakan bahwa penguasaan kosakata adalah kemampuan untuk memahami dan memaknai secara tepat suatu gagasan, baik secara lisan maupun tertulis.

Selanjutnya menurut

Harjasujana dan Mulyati (1997:

5) untuk menguji penguasaan kosakata seseorang bisa dilakukan dengan menggunakan teknik uji rumpang, yaitu melesapkan kata-kata dalam sebuah wacana. Untuk mengukur penguasaan kosakata teknik uji rumpang digunakan rumus.

$\frac{\text { Jumlah jawaban benar }}{\text { Jumlah kata yang dilesapkan }} \times 100$

\section{METODE}

Metode penelitian yang digunakan dalam penelitian ini adalah metode deskriptif korelasional. Metode deskriptif korelasional mempelajari hubungan antar variabel. Hasil dari penelitian kemudian akan diinterpretasikan dengan analisis deskriptif.

Populasi dalam penelitian ini adalah siswa kelas X IPA 6 SMA Negeri 1 Curup yang terdiri dari 30 orang siswa.

Selanjutnya pengambilan sampel dengan menggunakan sampel jenuh, yaitu keseluruhan dari populasi yang berjumlah 30 orang siswa.

Dalam penelitian ini ada 2 data yang dijaring yaitu penguasaan kosakata dan kemampuan membaca cepat. Instrumen yang digunakan untuk mengambil data penguasaan kosakata yaitu tes dengan menggunakan teknik uji rumpang yaitu menggunakan kurang lebih 250 kata dalam sebuah teks yang selanjutnya kata-kata dalam teks tersebut ada yang dilesapkan. Kosakata yang diuji dalam penelitian ini adalah kosakata konsep yang sesuai dengan 5 bidang teks yang telah disediakan. Kosakata konsep yang dilesapkan dalam 5 teks tersebut dapat diisi dengan menggunakan sinonim dan kata-kata yang paling tepat sesuai dengan pendapat Heaton (1988).

Instrumen yang digunakan untuk mengambil data kemampuan membaca cepat melalui tes membaca teks yang telah disediakan, terdiri dari 5 bidang, yaitu teks bidang budaya, teknologi, ekonomi, sosial dan sains. Siswa diminta untuk membaca teks tersebut dan menghitung waktu yang digunakan saat membaca menggunakan stopwatch. Instrumen yang digunakan untuk mengambil data pemahaman isi 
bacaan yaitu tes pilihan berganda dengan 4 pilihan berdasarkan isi teks yang telah disediakan berjumlah 10 soal pada masingmasing teks, untuk setiap jawaban benar maka diberi skor 1 dan jawaban salah diberi skor 0 .

Sebelum digunakan untuk penelitian, instrumen melalui tahap uji coba. Uji coba teks untuk teks terlebih dahulu diuji menggunakan grafik fry dan uji rumpang. Sedangkan untuk butir soal diuji validitas, reliabilitas, daya beda, dan tingkat kesukaran.

Analisis data penelitian dilakukan dengan menghitung skor kemampuan membaca cepat (KEM) yang menggunakan rumus

$\frac{\text { Jumlah kata dalam teks }}{\text { Waktu baca per menit }} X \ldots . . \%$ Pemahaman $=\cdots \mathrm{Kpm}$

Selanjutnya menghitung penguasaan kosakata dengan rumus

$$
\frac{\text { Jumlah jawaban benar }}{\text { Jumlah kata yang dilesapkan }} \times 100
$$

Hasil perhitungan kedua variabel tersebut selanjutnya dicari hubungan antara kedua variabel tersebut dengan menggunakan rumus korelasi product moment dengan nilai simpangan.

$$
r_{x y}=\frac{\Sigma x y}{\sqrt{(\Sigma x 2)(\Sigma y 2)}}
$$

Keterangan:

$r_{x y} \quad:$ koefisien korelasi

$$
\begin{array}{ll}
\mathrm{X} & : \mathrm{X}-\mathrm{X}^{-} \\
\mathrm{Y} & : \mathrm{Y}^{-} \\
\mathrm{X} & : \text { Skor rata-rata dari } \mathrm{X} \\
\mathrm{Y} & : \text { Skor rata-rata dari } \mathrm{Y}
\end{array}
$$

\section{HASIL DAN PEMBAHASAN}

1. Penguasaan Kosakata

Tes penguasaan kosakata diperoleh dengan tes uji rumpang dengan jumlah sampel sebanyak 30 siswa adalah sebagai berikut.

Skor tertinggi: 86.2
Skor terendah: 60.91

Mean (M): 69.11

Median (Me): 67.81

Modus (Mo): 60.91

Standar Deviasi (SD): 6.4

Jumlah kelas interval yaitu ada 6 .

Rentang data dihitung sebesar 25.29.

\begin{tabular}{|c|c|c|c|}
\hline No & Interval & $\mathrm{F}$ & $\%$ \\
\hline 1. & $82.1-86.22$ & 1 & $3.33 \%$ \\
\hline 2. & $77.79-82$ & 1 & $3.33 \%$ \\
\hline 3. & $73.57-77.78$ & 6 & $20.00 \%$ \\
\hline 4. & $69.35-73.56$ & 5 & $16.66 \%$ \\
\hline 5. & $65.13-69.34$ & 10 & $33.33 \%$. \\
\hline 6. & $60.91-65.12$ & 7 & $23.33 \%$ \\
\hline \multicolumn{2}{|r|}{ Jumlah } & 30 & $100 \%$ \\
\hline
\end{tabular}
Sedangkan panjang kelas 4.21. Berikut ini disajikan distribusi frekuensi berdasarkan hasil analisis data.

Tabel1. Distribusi Frekuensi Variabel Penguasaan Kosakata penguasaan kosakata, menunjukan variabel penguasaan kosakata terletak pada interval 65.13 - 69.34 sebanyak 10 siswa (33.3\%) dan paling sedikit terletak pada interval 82.1 - 86.22 dan 77.79 82 masing-masing 1 orang siswa (3.3\%).

\begin{tabular}{|c|c|c|c|c|}
\hline \multirow{2}{*}{ No } & \multirow{2}{*}{ Skor } & \multicolumn{2}{|c|}{ Frekuensi } & \multirow{2}{*}{ Ket } \\
\hline & & $\mathrm{F}$ & $\%$ & \\
\hline 1. & $>66.66$ & 16 & $53.33 \%$ & Tinggi \\
\hline 2. & $\begin{array}{c}33.34- \\
66.66\end{array}$ & 14 & $46.66 \%$ & Sedang \\
\hline 3. & $<33.34$ & 0 & 0 & Rendah \\
\hline & otal & 30 & 100 & \\
\hline
\end{tabular}

Adapun kecenderungan skor variabel penguasaan kosakata dapat ditunjukan pada tabel berikut.

Tabel2. Distribusi Kategorisasi Variabel Penguasaan Kosakata

Data tabel di atas menunjukan kecendrungan frekuensi variabel penguasaan kosakata yang berada pada kategori tinggi sebanyak 16 siswa (53\%), penguasaan kosakata pada kategori sedang 
sebanyak 14 siswa (47\%) dan tidak ada siswa yang termasuk dalam penguasaan kosakata pada kategori rendah.

\section{Kemampuan Membaca Cepat}

Data hasil tes kemampuan membaca cepat diperoleh dengan tes membaca cepat dan tes pemahaman isi bacaan dengan jumlah sampel sebanyak 30 siswa. Berdasarkan data variabel kemampuan membaca cepat (KEM), diperoleh hasil sebagai berikut.

Skor tertinggi: 324.7

Skor terendah: 132.23

Mean (M): 224.87

Median (Me): 228.61

Modus (Mo): 285

Standar Deviasi (SD): 48.56

Jumlah kelas interval yaitu 6 kelas interval. Rentang data dihitung sebesar 192.47. Sedangkan panjang kelas 32.07. Berikut ini disajikan distribusi frekuensi berdasarkan hasil analisis data.

Tabel3. Distribusi Frekuensi Variabel Kemampuan Membaca Cepat (KEM)

\begin{tabular}{|c|c|c|c|}
\hline No & Interval & $\mathrm{F}$ & $\%$ \\
\hline 1. & $292.72-324.79$ & 3 & $10.00 \%$ \\
\hline 2. & $260.64-292.71$ & 4 & $13.33 \%$ \\
\hline 3. & $228.56-260.63$ & 8 & $26.66 \%$ \\
\hline 4. & $196.48-228.55$ & 4 & $13.33 \%$. \\
\hline 5. & $164.4-196.47$ & 9 & $30.00 \%$ \\
\hline 6. & $132.23-164.3$ & 2 & $6.66 \%$ \\
\hline \multicolumn{2}{|c|}{ Jumlah } & 30 & $100 \%$ \\
\hline
\end{tabular}

Berdasarkan tabel distribusi frekuensi dan diagram batang kemampuan membaca cepat (KEM), mayoritas frekuensi variabel kemampuan membaca cepat (KEM) terletak pada interval 164.4 - 196.47 sebanyak 9 siswa (30\%) dan paling sedikit terletak pada interval 132.23 - 164.3 sebanyak 2 orang siswa (6.6\%).

Penentuan kecenderungan variabel kemampuan membaca cepat (KEM).

Tabel4. Distribusi Kategorisasi Variabel Kemampuan Membaca Cepat

\begin{tabular}{|c|c|c|c|c|}
\hline \multirow{2}{*}{ No } & \multirow{2}{*}{ Skor } & \multicolumn{2}{|c|}{ Frekuensi } & \multirow{2}{*}{ Ke } \\
\cline { 3 - 5 } & & $\mathrm{F}$ & $\%$ & \\
\hline 1. & $>221.6$ & 16 & $53.33 \%$ & Tinggi \\
\hline 2. & $198.4-221.6$ & 3 & $10.00 \%$ & Sedang \\
\hline 3. & $<198.4$ & 11 & $36.66 \%$ & Rendah \\
\hline \multicolumn{2}{|c|}{ Total } & 30 & 100 & \\
\hline
\end{tabular}

Berdasarkan tabel distribusi kecendrungan di atas, frekuensi variabel kemampuan membaca cepat (KEM) yang berada pada kategori tinggi sebanyak 16 siswa (53.33\%), kemampuan membaca cepat (KEM) pada kategori sedang sebanyak 3 siswa (10\%) dan kemampuan membaca cepat (KEM) pada kategori rendah sebanyak 11 siswa (36.66\%).

3. Pengajuan Hipotesis

Hipotesis dalam penelitian ini adalah terdapat hubungan yang signifikan antara penguasaan kosakata dengan kemampuan membaca cepat siswa kelas X IPA 6 SMA Negeri 1 Curup. Dasar pengambilan keputusan menggunakan koefisien korelasi $\left(r_{x y}\right)$, untuk menguji signifikansi adalah dengan membandingkan nilai $r_{\text {hitung }}$ dengan $r_{\text {tabel }}$ pada taraf signifikansi $5 \%$. Jika nilai $r_{\text {hitung }}$ lebih besar dari nilai $r_{\text {tabel }}$ maka hubungan tersebut signifikan. Sebaliknya, jika nilai $r_{\text {hitung }}$ lebih kecil dari $r_{\text {tabel }}$ maka hubungan tersebut tidak signifikan. Untuk menguji hipotesis tersebut maka digunakan analisis korelasi Product Moment.

Tabel5. Ringkasan Hasil korelasi Product Moment

\begin{tabular}{|l|l|l|l|}
\hline No. & Variabel & $r_{\text {hitung }}$ & $\begin{array}{l}\mathrm{r}_{\text {tabel }} \\
\mathrm{N}=30 \\
\mathrm{Sig}=5 \%\end{array}$ \\
\hline 1. & $\begin{array}{l}\text { Penguasaan } \\
\text { Kosakata dengan } \\
\text { Kemampuan } \\
\text { Membaca Cepat }\end{array}$ & 0.53 & 0.361 \\
\hline
\end{tabular}

Hasil korelasi product moment menunjukkan taraf signifikansi sebesar 0,53 , sedangkan $r_{\text {tabel }}$ pada taraf signifikasi 
$5 \%$ dan $\mathrm{N}=30$ adalah 0.361 . Hasil analisis tersebut terlihat bahwa nilai $r_{\text {hitung }}$ lebih besar dari $r_{\text {tabel }}(0,53>0,361)$. Sehingga dari hasil yang diperoleh tersebut dapat dinyatakan bahwa hipotesis alternatif $(\mathrm{Ha})$ yang berbunyi "terdapat hubungan yang signifikan antara penguasaan kosakata dengan kemampuan membaca cepat siswa kelas X IPA 6 SMA Negeri 1 Curup" diterima, sedangkan hipotesis nol $(\mathrm{HO})$ yang berbunyi "tidak terdapat hubungan yang signifikan antara penguasaan kosakata dengan kemampuan membaca cepat siswa kelas X IPA 6 SMA Negeri 1 Curup", dinyakatakan ditolak.

Hal ini sejalan dengan pendapat Djiwandono (1996:43) yang menyatakan bahwa pemahaman yang tepat terhadap pesan yang disampaikan melalui bahasa, banyak ditentukan oleh pemahaman yang tepat terhadap kosakata yang digunakan di dalamnya. Selanjutnya Tarigan (1985: 2) juga menyatakan bahwa kualitas keterampilan berbahasa seseorang jelas bergantung pada kuantitas dan kualitas kosakata yang dimilikinya. Dengan demikian, dalam hal kemampuan membaca cepat yang menuntut kecepatan dan pemahaman isi bacaan, penguasaan kosakata memang memegang peranan penting untuk memahami dan memaknai setiap kata dan gagasan yang terdapat dalam sebuah teks.

\section{PENUTUP}

\section{Kesimpulan}

Kesimpulan yang dapat diambil dari hasil analisis yang dilakukan adalah sebagai berikut.

1. Penguasaan kosakata siswa kelas X IPA 6 SMA Negeri 1 Curup secara keseluruahan memperoleh skor ratarata 69.11 yang termasuk dalam kategori tinggi. Sejumlah 53\% penguasaan kosakata siswa masuk pada kategori tinggi, $47 \%$ penguasaan kosakata siswa masuk pada kategori sedang, dan tidak ada siswa yang penguasaan kosakata nya masuk pada kategori rendah.

2. Kemampuan membaca cepat (KEM) siswa kelas X IPA 6 SMA Negeri 1 Curup secara keseluruahan memperoleh skor rata-rata $224.87 \mathrm{Kpm}$ dengan kategori tinggi. Sejumlah 16 siswa (53\%) yang masuk dalam kategori tinggi, 3 siswa (10\%) dalam kategori sedang dan 11 siswa (37\%) dalam kategori rendah.

3. Terdapat hubungan yang signifikan antara penguasaan kosakata dengan kemampuan membaca cepat (KEM) siswa kelas X IPA 6 SMA Negeri 1 Curup sebesar 0,53 $\left(r_{\text {hitung }}=0,53\right.$ pada taraf nyata $\alpha=0,05$ dengan $\mathrm{N}=30, r_{\text {tabel }}=$ 0,361, dan $\left.r_{h}>r_{t}\right)$.

\section{Saran}

1. Bagi Siswa

Siswa diharapkan dapat meningkatkan atau menambah perbendaharaan kosakata yang dimiliki, banyak membaca akan menambah wawasan dan menambah perbendaharaan kosakata. Siswa diharapkan terus melakukan kegiatan latihan membaca cepat agar dapat meningkatkan kemampuan membaca cepatnya. Penguasaan kosakata dan kemampuan membaca cepat yang baik akan membantu meningkatkan prestasi belajar siswa.

2. Bagi Guru Bahasa Indonesia

Guru diharapkan dapat memperhatikan dan membantu proses penambahan perbendaharaan kosakata yang dimiliki oleh siswa dengan latihan dan tugas-tugas. Selanjutnya guru diharapkan mampu menumbuhkan minat baca para siswa. Guru harus memberikan banyak pengetahuan mengenai membaca cepat, baik teori maupun praktik agar siswa dapat memahami, menguasai dan menerapkan kegiatan membaca cepat. 
3. Bagi Sekolah

Mengingat masih rendahnya kemampuan membaca cepat yang dimiliki oleh siswa, maka diharapkan pihak sekolah dapat mengadakan program-program khusus baik yang bersifat akademik maupun nonakademik seperti kegiatan pelatihan membaca yang difokuskan untuk menambah perbendaharaan kosakata dan meningkatkan kemampuan membaca cepat siswa.

\section{DAFTAR PUSTAKA}

Ahmad, Listiyanto. 2010. Speed Reading Teknik dan Metode Membaca Cepat. Yogyakarta: A+Plus Books.

Dalman. 2013. Keterampilan Membaca. Jakarta: PT Raja Grafindo Persada.

Djiwandono, M Soenardi. 1996. Tes Bahasa dalam Pengajaran. Bandung: ITB.

Harjasujana dan Yeti Mulyati. 1996. Membaca 2. Jakarta: Departemen Pendidikan dan Kebudayaan.
Harjasujana dan Yeti Mulyati. 1997. Membaca 2. Jakarta: Departemen Pendidikan dan Kebudayaan.

Heaton, J. B. 1988. Writing English Language Tests. New York: Longman.

Somadayo, Samsu. 2011. Strategi dan Teknik Pembelajaran Membaca. Yogyakarta: Graha IImu.

Tarigan, H.G. 1985. Pengajaran Kosakata. Bandung: Angkasa.

Trianto, Agus. 2004. Pengembangan Kompetensi Berbahasa Bahasa Indonesia Untuk Kelas 1 SLTP. Bengkulu: Universitas Bengkulu.

Widiatmoko, Irwan. 2011. Super Speed Reading Metode Lengkap dan Praktis untuk Meningkatkan Kemampuan Membaca. Jakarta: PT Gramedia Pustaka Utama. 